\title{
Succession Strategy for Sustainability of the Family Business
}

\author{
Lozano Fuentes Luis Javier ${ }^{1}$, Josefina Morgan Beltrán ${ }^{2 *}$ \\ ${ }^{1}$ Student of the Doctorate in Economic and Administrative Sciences from the Autonomous University of \\ Querétaro, Mexico \\ ${ }^{2}$ Doctorate in Administration and post-doctorate in Education, research professor at the Autonomous University \\ of Querétaro, Mexico
}

*Corresponding Author: Josefina Morgan Beltrán, PhD in Administration and post-doctorate in Education, research professor at the Autonomous University of Querétaro, Mexico

\begin{abstract}
How can the succession process be carried out in a family business to strengthen its sustainability over time? The aim of this paper is to analyze the succession of family businesses to increase the chances of success through the combined application of model s succession; The combine models such as that of the three circles, that of succession and aspects such as protocols; this is a research with a qualitative approach using the case study method, phenomenology and document analysis and applying the techniques of open interview and observation, the information obtained and analyzed makes it possible to conclude that by combining the models studied, the possibiities of successful succession are increased since aspects are dealt with in a broader way than individually do not cover the models themselves.
\end{abstract}

Keywords: Succession Strategies, Family Businesses, Sustainability

\section{INTRODUCTION}

This article starts from the complexity that family businesses have with the succession, that is, the transmission to the next generation. So it is important to look for alternatives to make successions more successful, Its objective is to analyze the succession of family businesses to increase the chances of success through the combined application of succession models like Belausteguigoitia (2012) in which identifies five stages, diagnosis, planning, training, transfer and completion and model of the three circles. Tagiuri (1996) which shows the interrelationship of the three roles involved in family businesses, which are: family, owners and employees. Family businesses are of vital importance for the economy of any country and unfortunately a high percentage of these businesses fail when the generational change is made, so it is important to try to find alternatives so that the succession is carried out successfully and these can continue to grow and creating jobs to continue supporting the economies of the countries. This research work has a qualitative approach and the case study method was used in family organizations, the phenomenology and the analysis of documents applying the techniques of open interview and observation, the family business owners and the advisor were interviewed for purposes of triangulation of information. The information obtained and analyzed makes it possible to conclude that by combining the two models studied, the chances of the succession being successful are increased, since aspects are dealt with in a much broader way than individually the models do not cover them.

The family is one of the pillars of any society and any economy in the world, however, its definition is not so simple because of cultural aspects and differences that exist throughout the world. Even for the United Nations (UN), it does not have a single concept of family, although it speaks of its importance and in 1994 under the motto "Family, resources and responsibilities in an evolving world", they proclaim it as "Year International of the Family ". The aim of this proclamation was to promote measures worldwide in order to improve the condition of the family. This initiative was aimed at increasing the understanding of family issues and one of those topics is: "family businesses".

\section{THEORETICAL ASPECTS}

\subsection{Theoretical Considerations on the Succession of Family Businesses}

From 1960 and 1980 arise consultants and research focused on the problems of family businesses, in the same way there are several definitions of what is a family business, from very simple as proposed 
Belaustegui g oitia (2012) that says " A family business is an organization controlled and operated by the members of a family." (P.33) Or the one that says that "Family businesses are the entire range of companies in which an entrepreneur or general manager of the next generation and one or more family members have a significant influence on the company." (Poza, 2011, p.5).

According to the Bulletin of the commission of Development Family Business advisors (La Salle, 2014) family businesses generate approximately 50\% of GDP worldwide and in Mexico it is estimated that $90 \%$ of established Mexican companies are family businesses, so it shows the importance of these businesses for the economy and livelihood of a country. Due to cultural issues in our country, the family is considered as a driving force for the development of individuals, which is why, from the family, more complex organizations are developed.

There are two key elements that make Family Business, the need for control and influence on it by the family and, secondly, the existence of business values that have to do with the possession and ownership of the economic entity that entail to the need to transfer from generation to generation ( Tapies , 2011). The Family Business is understood as an organization formed and directed by one or several members of a family; standing out the existence of a group of shareholders that requires and demands to establish goals and define the nature of a business that allows it to overcome limits and create a truly profitable activity. In addition, it is of vital importance to emphasize that in the decision making within the Family Businesses an in-depth evaluation of the implications of the three main elements of this type of economic entities is required: the family, the property and the company.

Inter-family relationships are very important for the success of this type of business and can be a competitive advantage over non-family businesses, to start this kind of business where it is only the founder is relatively simple because the decision depends only of this one, however when children are incorporated into the business decisions are becoming increasingly complex and to say when more families are incorporated, as they could be, wives, husbands and cousins among others, is still more complicated tom decisions. This happens because the roles are confused within the company, the general director can be the founder, but also the pope and sometimes the son, who is one more employee can confuse or take advantage of this situation to manage that family relationship to its convenience and not always for the benefit of the business and this must be added to the employees who are not relatives and who realize what is happening and how this relationship affects the business at times.

According to Trevinyo (2010) in Mexico 50\% of family businesses experience problems of succession in the transition from the first to the second generation and the failure of these businesses is $75 \%$, and most disappear when the founder dies. This phenomenon is worldwide and Mexico is not the exception.

For Trevinyo (2010) some of the most frequent problems experienced by this type of business are: structural and cash flow problems, lack of information in accounting, legal and tax matters, conflicts in the family, problems of strategic planning and problems of succession among others. Araya (2011) highlights three main impacts in the generational context:

- The intransigence or resistance of the founder to accept his withdrawal and deliver the courier to the successor for not having clearly planned this transition;

- Tensions between the founder and his descendants by the designation of the successor for not having planned it adequately and

- The consequences in the deterioration of relations of those who remain as successors; and, tensions between the same relatives for the designation of the successor.

Succession is one of the most important when discussing family business issues, according to Trevynio (2010) "The succession is a dynamic process during which the roles and tasks of the predecessor and the successor evolve independently in parallel until they intersect and overlap or splice" (p.200). When succession is planned, it must be very objective to designate the person have the ability, the ability and vision to guide the company to achieve its potential according to economic conditions and circumstances that are living at the time.

Sustainability according to the United Nations (1986), is "meeting the needs of the present generation without compromising the ability of future generations to meet their own needs " and emerges as a 
basic principle for long-term global development, its main pillars are the balance of 3 fundamental factors that are the Economic, Social Development and the Protection of the Environment.

For this research sustainability is considered as the actions that family businesses should take now to ensure its continuity over time, that the company remains, continues and is successful, is the search for strategies that allow making current decisions that not only do not compromise the life and existence of the company itself but allow it to live, survive in time as well as adapt to the needs that arise from competitiveness and globalization to avoid disappearing.

\section{SOME MODELS FOR THE SUCCESSION OF FAMILY BUSINESSES}

\subsection{Model of Belausteguingoitia}

Belausteguigoitia (2012) develops a model of family succession (Figure 1 that clearly explains the stages through which the succession must pass.

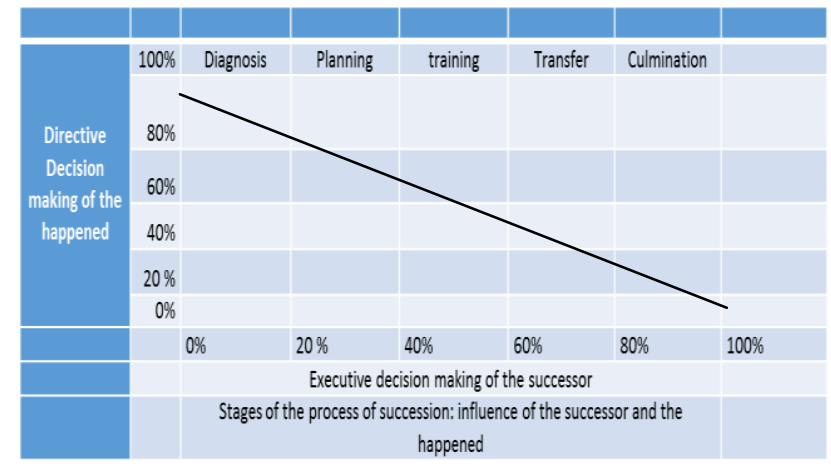

Figure1. Process of family succession

Source: Belausteguigoitia (2012, p. 224).

In the diagnosis stage the founder begins to evaluate several aspects such as: if any of the children is capable and if they are interested in continuing with the business, if the business is large and profitable enough to support all the children and their families, if you really want to continue with the business or simply sell it when you can no longer handle it, what characteristics and what profile the child should have that will happen, at this stage the founder has to reflect on where he sees his business in the future and how he intends to do it. As we can see in this stage of the model, the decision and reflection fall $100 \%$ on the founder.

In the next stage, which is planning, a very clear plan of the succession must be drawn up, it is important that all those who have the possibility of being the successor, get involved in the elaboration of this plan, in this way the risk is reduced of creating gangs or family problems that usually happen because of envy or jealousy and increases the legitimacy of the process. The plan should include the design of the desired organization and the profiles of future directors.

In the training phase, it is important that, since the profiles of the position and the designated successor are available, that they are trained through courses, diplomas, master's degrees or any other type of training related to the activities they will perform. in the new position. It is important that you have work experience and it is much better that this experience has been acquired outside the family business, regardless of whether you are getting involved little by little with the family business or in different areas of the business.

In the transfer stage, a double command is experienced since both the successor and the successor make decisions related to the management of the company and there is a lot of tension because there may be confusions of the personnel in the company. It is very important that there is a lot of communication between those involved so that this stage is carried out in the most friendly and effective way possible.

The last stage that is the culmination and that seems the simplest to be the final, is not always so, because if one of the parties is not ready to take on its new role may fail all the work done in the other stages. What happens if the person is not happy in the new role of retired and wants to return? What happens if the successor at the time of taking $100 \%$ the reins of the business do not feel safe? 
In this model, it can be clearly observed that as the succession progresses, the successor acquires greater importance in decision-making until all of them fall back on it, taking this task away from the event. It can also be observed that succession is not an easy task and that it is not done in a short period, but on the contrary, it is a task that involves a lot of dedication and time to really be successful.

\subsection{Model of the Three Circles}

For Tagiuri and Davis (1996) who have seen how complicated this relationship between owners, family members can be, Managers and employees designed a model that clearly shows how the different participants of family businesses overlap and interact (Figure 2) .

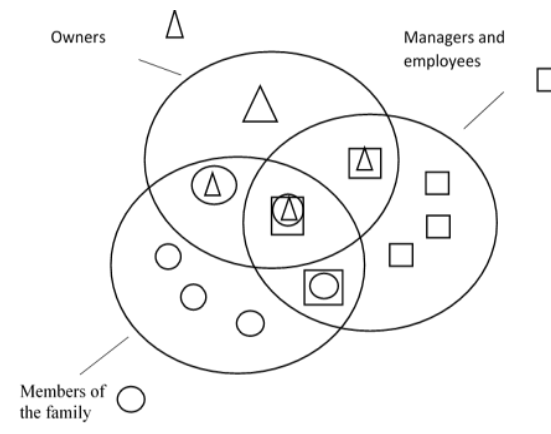

Figure2. Model of the three circles

Source: Tagiuri and Davis (1996)

It can be seen in this model of the three circles that there are three main participants in family businesses that are Employees, family members and owners or shareholders. If you look at each of the participants separately, you would be playing a single role in the company and this would not be very complicated, but it would not be entirely accurate either, as these circles are intertwined, which is what happens in real life in family businesses. They overlap the roles of the different members of the family businesses and 7 subgroups or 7 different roles are created in the company. You have the employee-shareholder, the shareholder-member of the family, the family-employee member and the family member, shareholder and employee, which makes the interrelation in family businesses complicated. To try to understand better the importance of this model, we will try to explain the different implications in which the participants of the family businesses are involved (Tagiuri and Davis, 1996).

Because the circles are intertwined with the participants that were previously mentioned, the roles or simultaneous roles they play a very important role in the performance of the company, since they have 3 roles at the same time, like owners, managers and family members and for that same reason their priorities change according to the role they are playing. As members of a family, they are more concerned with maintaining the harmony and unity of the same family, as owners are focused on the performance of their investment and as manager's focus on the proper functioning of the company and its employees. Because of performing various roles within the company, centralized decision-making can be obtained as a result and this can bring greater efficiency in the decision process. When the objectives are clear for the three participating groups, better results are achieved, however, the opposite can also be the case where the results are bad because each of the three participating groups has different priorities. Although the objectives are clear, there is always the risk that the family members get confused and fail to separate the family issues from the business and this causes some confusion among the members of the company regarding the responsibilities.

The shared identity in the company is a very important factor. Family members who work together share a sense of identity and this in some way commits them to a certain type of behavior inside and outside the company. The name of the family becomes a very important aspect that must be taken care of lot. Sometimes this becomes an extra pressure for some family members who feel they lose all freedom to act and tends to be a risk factor if you do not know how to handle this type of pressure, it can even create resentment.

The behavior of working together s family is somehow influenced by sharing a common life story and this cannot be separated by just wanting it, They have shared and lived many experiences, this has 
allowed them to know each other very well, to the extent that they know their strengths and weaknesses. This situation can be both positive and negative. Knowing each other so well can be of great benefit to the company because an understanding can be achieved that benefits the company in an important way, however, on the other hand, if there is a negative experience among the family members, it can become a serious problem. Seriously business because they will bring their old quarrels to work.

Members of a family working together emotional experience $\mathbf{r}$ elations and confusion at work, A s a result of having lived together for many years, family members have mixed feelings, both positive and negative for each of the family members. It is not unusual at work that emotions arise with family members more easily than with those who are not members of the family. In the case that the feelings are of affection and affection the potential of the relatives is enormous, since they can be very motivated and create a sense of loyalty and belonging very important and this brings as a consequence that the company is achieving its performance objectives, growth and recognition of the business. However, when the feelings are of spite or hatred the business can have many difficulties, since this feeling will affect in a very important way the performance of each one of the members of the family and more of those who are involved in the feeling, They will try to avoid themselves at work and also try to make each other look bad.

Among the members of a family, they know each other so well that they already have their own way of communicating with each other, so the private language between family members is important in family businesses. With a simple glance, with some movement of the body or simply with some phrase that they have between them can achieve a great result. This allows families to communicate more effectively and more quickly, which will result in a better performance of the work of family members. However, it can also have a negative side, since some gesture or movement can make some member of the family feel bad, so clear communication It is still very important to avoid misunderstandings.

Mutual Awareness and privacy are very common in family businesses, family members are usually very aware of personalities and characteristics, as well as very personal aspects of each one of the members of the family. This awareness is developed through the communication that exists between them, the language they have developed among family members over the years and that family members have other family members who share information. The more awareness there is regarding the situation of each member of the family, the communication will be much better because of the empathy that will develop between them. But so much awareness of the situation of a family member also has its downside because there is a risk that someone feels overwhelmed or pressured and this will bring negative consequences to the family business.

The meaning that family members give to Family Company It can be transcendent in business continuity. It is very important to consider the stage in which the business is located, in the case of the first generation the founder can see the company as his creation and have very strong feelings towards it. The son of the founder or his wife can $\mathrm{n}$ see the company as the creation of her fatheror her husband and also have very deep positive feelings, For the following generations, although there may also be positive feelings, it is not often that this happens, since they do not see it with the same affection and importance that this business had for the first generations. When there is not a system of promotions and adequate support for family members, there may be problems in the business, as rivalries between family members begin, in the first generation it may occur between the founder and his son, on the one hand the father does not want to leave the control and the son wants to have it, when this happens the family businesses can have serious problems that can lead to the closure of it.

The importance that the family gives to the family business and the communication that exists between the generations to really be able to transmit what it means and has meant the business for the family in all aspects, both economic and social is of vital importance for the success of it and the healthy coexistence among the family

\subsection{Family Protocol}

To complement the union of some of the models of Belausteguigoitia ( 2012) and Tagiuri and Davis (1996), it is essential to consider the establishment of formal family protocols (Lozano, 2000 ) that support the solidity that is sought in the continuity of the company through time, the clarity of expectations, mission, vision, philosophy, commitments, etc. will be critical to the success of the 
succession and continuity of the company in the market even become more competitive. This protocol gives continuity to the efforts made in the company by its founders and attempts to create a conceptual framework regarding the family's position vis-à-vis its own businesses.

According to Lozano (2000) the establishment of family protocols allows reducing the conflicts generated by uncertainty, clarifying the criteria for decision making, defining policies for strategic planning, helping to unify family and business interests and the most important thing is that can increase affection and family unity.

The protocol by itself if it is not accepted and respected by the members involved will not be of any use, also, it is important to consider in its preparation that the particular conditions of each family vary in aspects of substance and relevant to the establishment of the same and It suggests that the execution of the document be formalized before independent bodies such as Public Notaries or competent authorities in the matter.

The aspects to consider for the elaboration of a Strategic Plan and to formalize the rules of a family business according to Lozano $(2000$, p.3) are among others:

- The manifesto or family protocol.

- Strategic planning in the family business.

- Succession planning.

- Treatment of the intrafamiliar relationship.

- Implementation of the family assembly and the family council.

- Study of transitions within the family-business system.

- Knowledge of family business trends in the market.

The family protocol "is a written document that clearly sets out the values and the relationship between families and their policies regarding the company" (Lozano, 2000, p.5) andmanifests as Leach (1993) "Families that face the future together, and that they have clearly defined their goals and policies with respect to the company, have much more chances of success than those that only react to events".

The elaboration of the protocol requires the acceptance and immersion of the members of the family, for this it is necessary to consider aspects such as Freedom and equal opportunities to express what they think; Pact of Honor This aspect refers above all to the willingness to respect the decisions that are made by the majority even when these do not coincide with the particular ones; Values of the Family, in each family certain values and customs are promoted that are transmitted from generation to generation and that in some way keep it integrated and favor good relations; Intrafamily relationship, intrafamily harmony should be sought when making agreements and decisions, it is not advisable to carry them out when there are conflicts over power, if it is difficult to provide the conditions for it, the support of an expert and independent professional is suggested for it.

The minimum sections that a protocol must contain are: Content, in which all the aspects that the family considers convenient are considered, especially the family and performance aspects that are expected, financial aspects, behavior, policies and procedures, mission, vision , decisions, etc., General structure, is where they are given an order to the aspects and are detailed as much as possible to avoid confusion in the interpretation such as administration, benefits, participation, education, conflict resolution, code of ethics, framework of operation, board of directors, decision making, family conditions, commitments, additions of other family members, incursion and action of future family members and operation of the company in adverse conditions, scope and vision of growth and market penetration as well as the bases of the same, etc., Plan of execution of the protocol in which the bases of how to realize are established the points of the general structure such as: Training, Plan of succession and retirement, Socialization of the members of the family and transmission of values and the schedule to carry it out as well as the budgets and supervision, a revision of the conditions is recommended every 5 years and in the protocol it should be mentioned which are the points that will not be discussed and changed and which may be adapted to the current times of each update. 
With all this formal formalization of family agreements can be established not only for current members of families but for future generations and, the clarity and complete content of the points to be considered in each family, will depend on the success and Sustainability of the company through the times, these protocols must of course include the growth and scope of the company at a competitive level.

\section{Methodological Aspects}

Research is carried out under the Qualitative paradigm applying the Case Studies and Phenomenology methods, from the research question " In what way can the succession process be carried out in a family business to strengthen the sustainability of the same through of time? Semistructured personal interviews were conducted with managers and owners of the companies family business case studies and s expert or advisor is in family businesses, with the aim of triangular expert information and experiences.

The hypothesis considers that to be effective the succession of family businesses must be done through the combined application of a model of succession and a role model of family businesses

With this research it is intended that family businesses that are thinking about the issue of succession or that are experiencing it have tools that allow them to successfully achieve the transmission of business to the next generation.

\section{RESULTS}

In the interviews that were conducted, the results according to the codes of the Belausteguigoitia Model (2012) of the Succession that is diagnosis, planning, training, transfer and completion were the following:

Regarding the acceptance indicator that is part of the diagnosis is observed that it is emphasized that the business world is evolving and it is important to accept and act accordingly, it is important to accept the reality and at what stage the company is to start from there. In relation to capacity, the vision of the founders of putting the business ahead of the person is highlighted withthe best qualities to play it.

The training is a very important part for the succession and it is highlighted in the interviews that in the third generation the training has been through courses visits to fairs related to the business of the company and trips to other parts of the world to know different plants and know their operation. For future generations, (fourth generation) it is essential, in addition to the training that has been experienced, to complement it with postgraduate studies and preferably abroad. The commitment it's very important in successions, it was observed that for the people interviewed, their commitment is $100 \%$ with their company. The communication It has been very important for the success of the successions and one of the interviewees commented that what his grandfather and his father have transmitted to them has been key for the business to continue growing.

The continuation is the result of good planning in the succession and it is important to be aware and prepared to give the courier to the next generation, for the interviewees it is important that the founder be ready to let go of the business and leave control in the children, Otherwise, business will suffer a lot of damage, since these will stop evolving according to the new market conditions. As well highlights $\mathrm{n}$ that occurred must undertake new roles, such as seeking other activities or bringing new businesses to the family, says that the business will go ahead and if you have a team ready and institutional as was the case of Emilio Azcarraga Jean and Grupo Televisa which is one of the most successful family businesses in the country of Mexico.

The training is another very important aspect for the success of any business, aware of this one family contemplated that the next generation has postgraduate studies, as well as working first or outside the company and grab experience to later be incorporated into the family business and there rotate them by different positions and departments so that they have an integral knowledge of the business.

For some of the managers and according to their experience it is essential that there is a genuine interest of the founder to make the generational change, in their experience if there is no real interest the probability of success in the succession is almost nil, it is also important that children or successors show interest in integrating into the business.

The impartiality is an aspect of vital importance to the family business, success and family harmony is owed to the clarity and transparency with which they are doing business, no decision is not unanimous 
taken, seeks $\mathrm{n}$ always collective decisions and if they are not achieved, they prefer not to make the investment.

The profile of the successors is very important for entrepreneurs who are thinking about the succession, as stated by the interviewees, the founder usually does not have a specific profile because he was the creator of the business, but for the following generations and for managers It is very important to have the ideal person in each of the positions.

The planning is another key for the element succession model Belausteguigoitia (2012), so much that in some of the companies every 2 years reviewed with expert consultants in the field to see how they are going and what changes might be doing, always thinking about the business and the incorporation into the company of the next generation. Currently one of the families is planning to diversify their businesses, make each one an independent business unit and that can be led by a different captain, in that way they think integrate the new generation, and thus also be able to evaluate the performance of each business and that neither subsidizes the other business. Business that is not productive should not exist, likewise with children; if someone decides not to join the family, business is in total freedom to do what they most want, eg. Doctor. Planning 1 to explain $\mathrm{n}$ with a single concept, "Family Protocol", which is one document where business rules, a comprehensive and detailed way, they get from you need any family to join the business, and who, if they can and who can not, in what area they can and in what areas they do not, this document is indispensable and importantly diminishes the risks and conflicts in the succession. For the interviewed The succession process must start from before you have the business.

When talking about succession all the codes and all stages are very important, but like everything in life, the beginning is what determines where you are, how are you and from there starting where you want to go, so understanding the current situation of Business is essential for the success of it, both in the present and in the future. In the case of one of the s company s case studies, has n very clear in this regard, the roots of the business, currently have 3 areas of production, where they make preserves, one that is agricultural, divided into 2 areas, the open sky and greenhouses and finally the one that is responsible for marketing with their own transport equipment. From there they start for all the plans they have and that have already been discussed during this article.

For the manager this stage is also very important, it is basic, it is about knowing with certainty how the company is, for that reason the importance of the diagnosis, that is to say the current situation of the business, with all that this implies, from the interest of the founder to transcend and continue with the business through his family, even the interest of the children to continue with the family business. The advisor comments on the example of a client who has not been able to advance in the succession process, because, although the current situation of the business is explained to him and what has to be done for a successful succession, the founder refuses to do the necessary changes to achieve it.

For the interviewees it was crucial to know the current situation of the business, which is mainly to be aware that it is the company of all the brothers and that the family harmony is above the business itself, so understanding that, the business is walking with steps firm, although with a very slow dynamic, but with a lot of harmony and family unity.

\section{CONCLUSION}

As can be seen through this article, the succession in a family business is very complicated and many businesses fail to successfully navigate this process, are analyzed model succession of Belausteguigoitia (2012) and through interviews could observe its practical application in this type of business, starting with the diagnosis where the real situation of the business and the family is recognized, as well as the real disposition that exists on the part of the founder to pass the mail to the next generation, in the interview the family business consultant enfatiz or This aspect, " if the funder wants to continue being in control and even if his family members work in the business, the probability of successful succession is practically nil", likewise it was confirmed that planning is an indispensable part to see where you want to take the business. The training in future generations was mentioned in a very important way in the interviews and it is considered transcendental to achieve the long-term objectives. The same as the transfer and the culmination, where the control of the company is finally handed over to the successor by the happened one and this assumes a new role, but without interfering with the new direction. Also, analyzed the model of the three circles of Tagiuri (1996) to see the different roles that are played in family businesses, taking into account that 
there are 3 participants, owners, family and employees, it must be very clear in not mix those roles in the company if they want to achieve success, eg. The director general cannot treat his son in the company as a father, but as a boss, and the daughter cannot treat the brother as boss in the house, but as a brother, learning to identify these roles, and that each one is due perform in the appropriate place. This will not save the roles that correspond to them does great harm to business. In some businesses analyzed it is observed that children, in many times they use the role of children in the company of the pope not to do the work as they should and this causes them great harm to the business, since they are paying someone for doing something and do not do it, so someone more must be done and this generates an additional cost to the business that is detrimental to it and makes it not viable. As you can see the 2 models alone are very useful and are a great help to achieve succession in a family business; However, the combination of the two models analyzed here is more useful than independently, since it allows for more analysis deep of the different aspects that should be contemplated in a succession, the model of succession that involves the diagnosis, planning, training, transfer and completion can be applied to the three main roles played in family businesses. The diagnosis can be done in the family, What's family members are currently involved in the business?, What are your skills? What family members are out of business? Do they plan to join? Do they have the capacity? Those who are committed to the company, planning in the same way, What should be done with each of the family members? , In what position they are more Useful ?, Is it convenient to enter the business ?, In the same way we can combine the succession model with the role of Employee, in the diagnosis will analyze the characteristics of the employees as well as their contribution to the business, in planning, their potential to continue with the new requirements that the business will experience, your training will be key to continue supporting the transfer of command. And finally the combination of the models in the owners, with the diagnosis can be known Who of the owners work in the company? Who are family? Who thinks to work in the business? When? In the planning will be allowed to know what they expect from the business and where they intend to take and so in each of the stages of the succession model with the role of owner.

It is definitely observed that by combining the models, a much more in-depth analysis of all areas of the company is carried out through all its participants and this will ultimately allow a greater probability of success in the successions.

\section{REFERENCES}

[1] Belausteguigoitia, R. I. (2012) Family Businesses, its dynamics, balance and consolidation. (3rd ed.). Mexico: McGraw Hill Publishing House

[2] Tagiuri, R. and Davis, J. (1996). Bivalent attributes of the family firm. Family business review, 9 (2), 199-208.

[3] UN (2018). General Assembly Organization of the United Nations. Report «Our common future» of 1987 , World Commission on Environment and Development. President of the 65th session. Retrieved on February 10, 2018 from: http://www.un.org/es/ga/president/65/issues/sustdev.shtml

[4] Poza, Ernesto. (2011). Family Business . (3rd Ed.). Mexico: Editorial Cengage Learning.

[5] La Salle (2014) Bulletin of the commission of Development Family Business advisors.

[6] Tapies, J. (2011). Family business: a multidisciplinary approach. Universia Business Review , 4 (32).

[7] Trevinyo-Rodriguez, Rosa (2010) Family Businesses, Latin American Vision. Structure, management, growth and continuity. Mexico: Editorial Pearson.

[8] Araya, A. (2012). The Succession Process in the Family Business and its impact on the organization. Mexico: TEC Empresarial.

[9] Lozano, PM (2000). The Protocol in Family Owned Companies. Management Studies Magazine No. 74 of Ene-Mzo. 2000, from the ICESI University, taken from https://www.icesi.edu.co/revistas/index.php/ estudios_gerenciales/article/view/27/html

[10] Leach, P. (1993) . The Family Business . Spain: Editorial Garnica.

\section{Reference Materials}

[11] Alba Peña, Y. (2010). Business development of the family business case: Apan-The coffee plantation of the Coatepec region, Veracruz, accessed on April 19 from http://cdigital.uv.mx/handle/123456789/28921

[12] Andrade, JA (2002). Succession in the family business: Your future when death approaches. Venezuelan Magazine of Management , 7 (19).

[13] Brenes, E., \& Madrigal, K. (2003). Anticipating conflict in family businesses. INCAE Magazine , 12 (3), 5.

[14] Bulletin of the commission of Development Advisors of Family Businesses - La Salle, June 2014, ( 15 ). 
[15] Carmona, CAA Succession of Family Businesses. Retrieved on April 15 from http://www.alvarezcarmona. com/boletines /PDF_topico/DINAMICA\%20FAMILIAR.pdf

[16] Dodero, S. (2005). Research on the family business in Latin America. Institute of Family Business. ADEN Business School .

[17] Dodero, S. (2010). The life cycle of family businesses. Retrieved on May 9 from http://www.ucema.edu.ar /cimei-base/download/research/63_Dodero.pdf

[18] Dominguez, P. (2010). Succession in family businesses. Lima: PAD / School of Management of the University of Piura .

[19] Gallo, M. (2002). Evolution towards a family and multinational company. Research Seminar. University of Alicante, Department of Business Organization , 6 .

[20] Gallo, M. Á., \& De Rins, MAGL (1998). The succession in the family business (Vol. 12). " la Caixa".

[21] García, I. (2005). Study of Family Businesses in scenarios starting from the Evolutive Three-dimensional Model. Omnia , 11 (2).

[22] Geneva, J. (1997). Family businesses: their direction and continuity . Mexico , Editorial Panorama.

[23] Gómez-Betancourt, G., López Vergara, MP, \& Betancourt Ramírez, JB (2008). Exploratory study of the factors that influence the selection of a heritage succession mechanism in Colombian family businesses. C umdernos de Administración , 21 (37), 269-292.

[24] Ibarra, A, Ibarra D, Ibarra M. (2013). My Family in the Company "Everything you need to know about Family Relations within the Business" Mexico: My family in the Company. Mexico

[25] Kajihara, K. (2007). Family businesses: the Mexican business reality. ITAM Strategic Management Magazine, 1 (1).

[26] Lozano P. M. (2009). Elements for consulting in family businesses. Thought \& Management, (26), $214-237$.

[27] Manzano García, G., \& Ayala Calvo, JC (2002). Succession in the family business: Some keys to success. Bulletin of Economic Studies , 57 (177), 433-449.

[28] Pérez, A. (2012). The Family Business Model: The four fundamental pillars. Mexico, 3 Sciences. Published by Área de Innovación y Desarrollo, SL.consulted on March 20 from dialnet.unirioja.es/ descarga/articulo/4817932.pdf

[29] Ramón, JFC (2005). Manual of the family business . Spain, Editions Deusto.

[30] Rius, IB (2004). Family businesses: their dynamics, balance and consolidation . Mexico , McGraw-Hill.

[31] Rizo, M. (2015). The Best Kept Secrets of the Family Entrepreneur. Mexico: Grant Thornton

[32] Rizo, M. and Enciso, A. (2013). The successor. Mexico: Grant Thornton

[33] Rizo, M. and Enciso, A. (2014). The Successor II. Mexico: Grant Thornton

[34] Roibal, SB, Solórzano, EG, Feijoó, GD, \& Carballo, MM (2004). European vision of the succession process in the family business. Economic Bulletin of ICE, Spanish Commercial Information, (2822), 27-38.

[35] Room, Agusti. (2009). Family Secrets, The Wars of Power . Barcelona: Robinbook

[36] Tapies, J. and Ceja, L. (2011). Family protocols in Spanish-speaking countries: How they are and what they are used for (No. D / 931). IESE Business School.

[37] Ward, J. (2006). Success in family business. Editorial Norma.

\section{AUTHOR'S BIOGRAPHY}

Luis Javier Lozano Fuentes is a public accountant with a master's degree and a doctoral student in Economic and Administrative Sciences from the Autonomous University of Querétaro, Mexico.

Josefina Morgan Beltrán holds a doctorate in administration, post-doctorade in Education, belongs to the National System of level 1 Researchers in Mexico, and has 35 years of teaching experience and in the productive sector of the country. She is a research professor at the Universidad Autónoma de Querétaro, Mexico.

Citation: Lozano Fuentes Luis Javier, Josefina Morgan Beltrán,. "Succession Strategy for Sustainability of the Family Business" International Journal of Managerial Studies and Research (IJMSR), vol 6, no. 3, 2018, pp. 34-43. doi:http://dx.doi.org/10.20431/2349-0349.0603005.

Copyright: (C) 2018 Authors. This is an open-access article distributed under the terms of the Creative Commons Attribution License, which permits unrestricted use, distribution, and reproduction in any medium, provided the original author and source are credited. 